\title{
Student performance on the Test of Scientific Literacy Skills (TOSLS) does not change with assignment of a low-stakes grade
}

\author{
Verónica A. Segarra ${ }^{*}$, Nicole M. Hughes, Kristin M. Ackerman, Michael H. Grider, Todd Lyda \\ and Patrick A. Vigueira*
}

\begin{abstract}
Objective: Response-validated multiple-choice assessments are used in college courses to assess student learning gains. The ability of a test to accurately reflect student learning gains is highly dependent on the students' effort. Within our institution, lackluster student effort is common on response-validated multiple-choice concept assessments that are not included as a portion of the semester grade but are used to inform curricular changes. Thus, we set out to determine whether increasing testing stakes by assigning a grade on student performance had an effect on student score and self-reported effort. The Test of Scientific Literacy Skills (TOSLS) is a response-validated multiplechoice assessment used to measure scientific literacy in undergraduates. We administered the TOSLS to students enrolled in a general education Biology course, both during the first 2 weeks (pretest) and the last 2 weeks (posttest) of the course.
\end{abstract}

Results: Self-reported effort and TOSLS performance were significantly correlated in the ungraded cohort. This relationship did not exist in the graded sections. Our data indicate that assigning a low-stakes grade has no significant effect on mean student performance or self-reported effort on the TOSLS within our general education course.

Keywords: Test of Scientific Literacy Skills (TOSLS), Response-validated multiple-choice assessments, Low-stakes testing, No-stakes testing, Student effort

\section{Introduction}

In recent years, undergraduate institutions have sought to reform the curriculum of Biology courses according to recommendations from the American Association for the Advancement of Science Vision \& Change $(V \& C)$ in Undergraduate Biology Education Initiative [1-3]. At our institution we have also incorporated $\mathrm{V} \& \mathrm{C}$ recommendations into general education Biology courses including inquiry-based laboratory modules that allow students to experience science as a process, opportunities to engage with the content through active and collaborative

*Correspondence: vsegarra@highpoint.edu; pvigueir@highpoint.edu Department of Biology, High Point University, One University Parkway, High Point, NC 27268, USA learning methodologies, and additional opportunities for science communication.

Our ultimate goal is for our general education Biology courses to help non-science majors develop scientific literacy, the ability to identify data generated from scientifically-sound studies, and the ability to organize, analyze, and draw conclusions from this data [4]. In 2012 Gormally et al. [4] developed the Test of Scientific Literacy Skills (TOSLS) as a resource for biology instructors to evaluate their students' proficiencies in scientific literacy, including the identification and analysis of data that contributes to building scientific knowledge. We decided to use this tool to determine whether the curricular changes we were implementing were resulting in scientific literacy learning gains. 
Alongside using the TOSLS to assess learning gains related to scientific literacy, we also wanted to consider the effects of student effort and motivation on TOSLS performance. The ability of an assessment to accurately reflect student learning gains is dependent on student effort [5-9]. A student bringing his/her best effort to a test should translate into a performance that accurately reflects his/her true abilities and knowledge about the particular subject [7]. Within our institution, lackluster student effort is common on no-stakes standardized assessments that are used by instructors to inform curricular changes but do not contribute to a course grade. While student performance on these assessments has no effect on their course grade, we use their assessment scores to determine whether students have had gains in areas like scientific literacy. For this reason, we set out to determine whether increasing the testing stakes by assigning a low-stakes grade on TOSLS student performance would have an effect on student score and selfreported effort on the TOSLS. We hypothesized that increasing the stakes for students taking the TOSLS assessment would lead to higher reported student effort and higher student TOSLS scores. In addition, we did not believe that an increase in effort would impact the degree to which the students' TOSLS scores improved in the pretest/posttest analysis.

Before this study, the TOSLS was administered as a nostakes assessment; student performance on the TOSLS was not factored into the course grade and was therefore considered by the students to be of little or no consequence. Under these circumstances, we often noticed what appeared to be a lack of effort from students while taking the TOSLS (e.g. highly abbreviated testing time, obvious distraction, verbal assertion of disinterest). Student effort is known to influence whether or not a test score reflects a student's abilities and skills in a particular subject [10]. In fact, student effort can vary more widely in low-stakes testing [10]. For this reason, we sought to determine the effects of increased testing stakes on selfreported student effort and student TOSLS scores. We designed a controlled experiment in which the TOSLS was administered in a low-sakes testing environment; the TOSLS score was scaled to a mean of $90 \%$, maximum score of $100 \%$, and included as quiz grade (approximately $0.75-3 \%$ of the overall course grade). By using this grading policy, we attempted to establish a TOSLS grading policy that minimized testing anxiety in this inherently stressful situation to some students. We anticipated that students in graded sections may experience mild testing anxiety derived from their inability to specifically study or prepare for the TOSLS content.

\section{Main text \\ Methods \\ Participants}

Participants were volunteer students in a non-majors, general education Biology course at High Point University, NC, USA. Student participant demographics information was collected at the end of the post-assessments in an effort to minimize stereotype threat (Table 1). Students under the age of 18 were not allowed to participate in the study. A total of 14 course sections (164

Table 1 Demographic and class standing of participants in this study

\begin{tabular}{|c|c|c|c|c|c|c|c|}
\hline & & & \multicolumn{5}{|l|}{ Gender } \\
\hline & & & \multicolumn{2}{|l|}{ Female } & \multicolumn{2}{|l|}{ Male } & Other \\
\hline No grade & \multicolumn{4}{|c|}{68} & \multicolumn{2}{|l|}{15} & 0 \\
\hline Grade & \multicolumn{4}{|c|}{57} & \multicolumn{2}{|l|}{24} & 0 \\
\hline \multirow[t]{3}{*}{ Total } & \multicolumn{4}{|c|}{125} & \multicolumn{2}{|l|}{39} & 0 \\
\hline & \multicolumn{7}{|l|}{ Race } \\
\hline & \multicolumn{2}{|l|}{ Asian } & Black & Hispanic & Native American & White & Other \\
\hline No grade & \multicolumn{2}{|l|}{2} & 10 & 0 & 0 & 71 & 0 \\
\hline Grade & 2 & & 6 & 6 & 1 & 65 & 1 \\
\hline \multirow[t]{3}{*}{ Total } & 4 & & 16 & 6 & 1 & 136 & 1 \\
\hline & & \multicolumn{6}{|l|}{ Class } \\
\hline & & \multicolumn{2}{|l|}{ Freshman } & Sophomore & \multicolumn{2}{|c|}{ Junior } & Senior \\
\hline No grade & \multicolumn{3}{|c|}{56} & 21 & \multicolumn{2}{|l|}{5} & 1 \\
\hline Grade & \multicolumn{3}{|c|}{48} & 25 & \multicolumn{2}{|l|}{4} & 4 \\
\hline Total & \multicolumn{3}{|c|}{104} & 46 & \multicolumn{2}{|l|}{9} & 5 \\
\hline
\end{tabular}

Numbers correspond to number of individuals 
students) participated in this study. Only data from consenting students that completed both the pretest and posttest were included in our analyses. These sections were taught by five instructors in the fall semester of 2015 and the spring semester of 2017. 7 of these sections (83 students) were not assigned a grade for their TOSLS performance, while 7 of these sections (81 students) were assigned a grade for their TOSLS performance. In order to minimize the impact of inter-instructor variability on our study, individual instructors were assigned nearly equal numbers of graded and non-graded sections.

\section{Data collection}

The TOSLS assessment was administered to participants in a pretest/posttest format in the first and last meetings of the laboratory course component of a nonmajors, general education Biology course at High Point University, NC, USA. The TOSLS was administered using the Qualtrics (Provo, Utah, US) software system on the students' personal laptop or tablet computers. The TOSLS contains 28 multiple choice questions with a time limit of $35 \mathrm{~min}$. Following a brief introduction to the assessment instrument and our study, students simultaneously initiated the timed portion of the test and were given a verbal notification when $5 \mathrm{~min}$ remained in the testing period. Immediately following the completion of the TOSLS, all students were asked to complete a short survey that contained questions related to effort. We collected data on student effort by asking students the following radio button style question upon the completion of the TOSLS assessment: On a scale of 0-10 indicate the level of effort you exerted on this assessment $(0=$ none, $10=$ maximum effort $)$. Self-reported effort values are an effective way to measure effort, yielding similar values to other methods such as response time effort (RTE) [11].

Prior to the initiation of the test, students in graded sections were informed that the percentage of correct answers from the TOSLS assessment would count as a quiz grade (approximately $0.75-3 \%$ of the overall course grade). Because the students would not be given the opportunity to prepare for the TOSLS, we expected to encounter some testing anxiety amongst the grade-conscious members of the class. In an effort to minimize the detrimental effects of testing anxiety, we announced our grading plan to scale the mean score of each section to $90 \%$, with a maximum score of $100 \%$. In both graded and ungraded sections, students were verbally encouraged to take the test seriously by emphasizing the importance of the TOSLS assessment to departmental and universitylevel curricular decisions.

\section{Data analysis}

These experiments and their analysis were not blinded/ randomized. Data were tested for normality using Shapiro-Wilk test using JMP (Statistical Analysis Software, Cary, NC), and normality was determined as $\mathrm{P}>0.05$. When data were not normally distributed and could not be transformed to achieve normality, non-parametric analyses were used.

Mean test scores were compared using a mixed repeated-measures ANOVA in SPSS (SPSS Inc., Chicago, IL, USA). Grade condition (grade/no grade) was used as the between-subjects factor, and test condition (pretest/posttest) as the within-subjects factor. The interaction between grade and test condition was also tested in the same model. One-tailed, paired t-tests were used as post-hoc tests to determine which group(s) showed significant gains between the pretest and posttest. Mean effort on the pretest and posttest for the grade/no grade groups was compared using KruskalWallis test in StatsDirect (StatsDirect, Cheshire, UK).
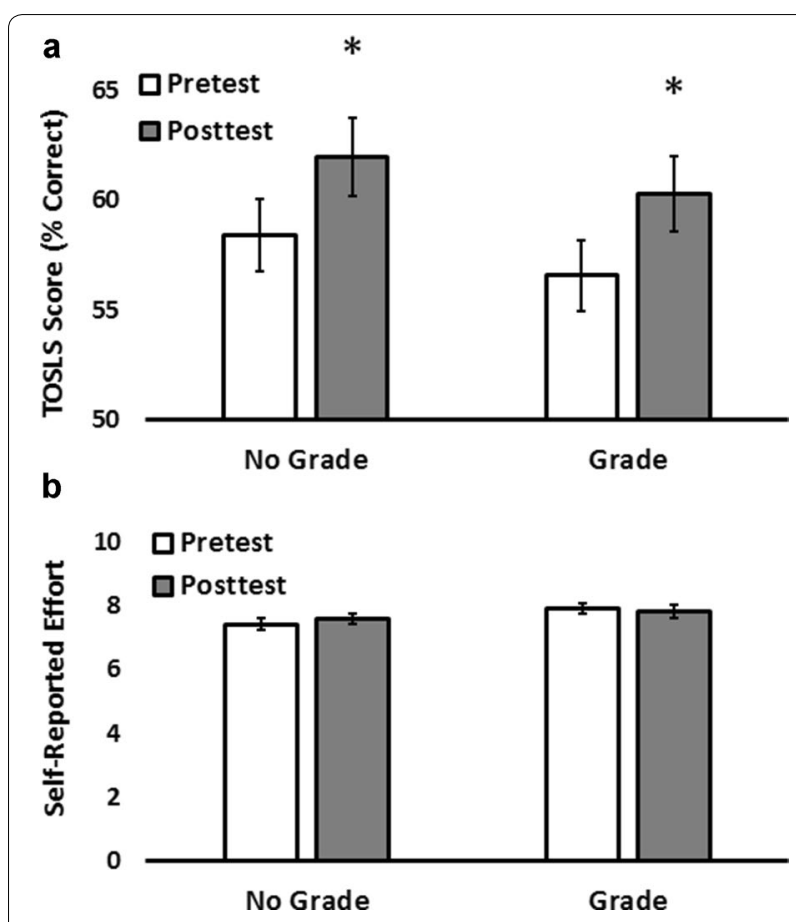

Fig. 1 Assigning a grade had no significant effect on student performance (a) or self-reported effort (b) on the TOSLS within our general education Biology course. Repeated measures ANOVA showed no significant effect of grade/no grade on score $(P=0.416)$ or self-reported effort $(P=0.18)$. There was a significant difference between the pretest and posttest scores in both models $(P=0.001)$. Pair-wise comparisons were made with post-hoc, paired t-tests. Error bars represent standard error of the mean. Asterisks denote significant differences between pretest and posttest scores as determined by post hoc paired t-tests. $P<0.01$ for no grade, and 0.005 for grade 


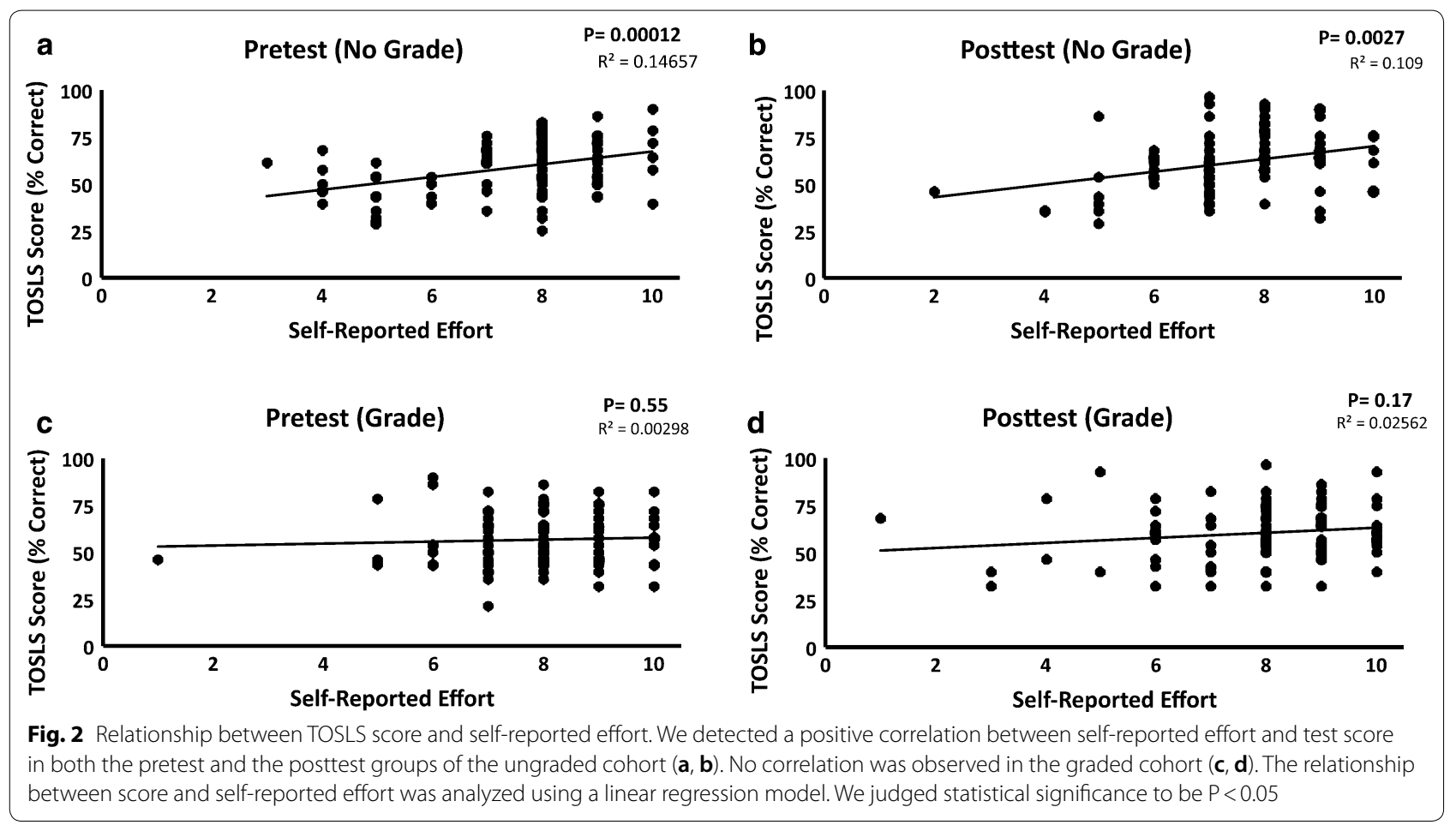

A non-parametric linear regression was used to examine the correlation between effort and test score for each of the four groups (grade/no grade and pretest/posttest) using StatsDirect software. In all analyses, $\mathrm{P}$ values less than 0.05 were considered significant.

\section{Results}

Pre and post-scores for both groups were normally distributed. There was no significant effect of grade condition (grade/no grade) on test score $(F(1,162)=0.665$, $\mathrm{P}=0.416)$. There was a significant effect of test condition (pretest/posttest) on test scores $(\mathrm{F}(1,162)=12.2$, $\mathrm{P}=0.001$ ), with posttests being significantly higher than pretests. There was no significant interaction effect of grade condition (grade/no grade) and test condition (pretest/posttest) on test score $(F(1,162)=0.004$, $\mathrm{P}=0.949)$. Paired t-tests showed that both grade and no grade groups showed significant gains between the pretest and posttest $(\mathrm{P}<0.01$ for no grade, $\mathrm{P}=0.005$ for grade).

There was no significant difference in effort reported by students in any of the four test groups (Fig. $1 \mathrm{~b} ; \mathrm{P}=0.18$ ).

\section{Discussion}

We use the TOSLS assessment every semester to measure student gains in scientific literacy in the context of our general education Biology courses. In general, this is done by administering a pre-semester and postsemester TOSLS assessment and looking for a statistically significant increase in mean student scores. We use this data to inform curricular changes and innovations that favor gains in scientific literacy.

We saw no difference in the average student TOSLS scores (Fig. 1a) or self-reported student effort (Fig. 1b) when comparing the sections that received a grade and those that did not. These data indicate that assigning a grade had no significant effect on mean student performance or student self-reported effort on the TOSLS within our general education course in the context of the described TOSLS grading policy. Interestingly, we found that there was a significant, positive correlation between self-reported effort and test score in both the pretest and posttest groups in the ungraded cohort (Fig. 2a, b). However, this relationship was absent in the graded sections (Fig. 2c, d). While our study did not include an assessment of testing anxiety, it is a welldocumented phenomenon that has been reported to reduce testing performance [12]. Thus, stress derived from our grading policy and resulting reduction in testing performance could account for the lack of association between self-reported effort and TOSLS performance in the graded cohort.

Alternative TOSLS grading policies that could be tested in the future include not curving the quiz at all, increasing the portion of the course grade that relies 
on TOSLS performance, and having the TOSLS performance grade be based off of improvement on the TOSLS raw score when comparing pre/post-examinations. Would changes in our grading policy affect TOSLS scores or self-reported student effort? While it is impossible to predict changes in TOSLS student scores as a response to further increases in stakes or value, previous literature in the field shows that, in the context of low-stakes testing, the cognitive demand of a particular assessment trumps the value students assign to a particular assessment [10].

Overall, these results suggest that in spite of a visible lack of student investment in ungraded assessments, the process of standardized testing before and after course completion still provides a relatively consistent and accurate measure of student gains.

\section{Limitations}

This study was conducted at a single university, and results may not be typical of other universities with different student populations.

\section{Abbreviations}

TOSLS: Test of Scientific Literacy Skills; V\&C: Vision \& Change in Undergraduate Biology Education Initiative.

\section{Authors' contributions}

PAV conceived and designed the study. VAS wrote the manuscript. NMH performed the statistical analysis. PAV, VAS, KMA, MHG, and TL participated in data collection. All authors edited this manuscript. All authors read and approved this manuscript.

\section{Acknowledgements}

The authors would like to thank the students who participated in this study. We also thank Lara Kammrath for helpful discussions about statistics.

\section{Competing interests}

The authors declare that they have no competing interests.

\section{Availability of data and materials}

The datasets generated and/or analyzed during this study are not publicly available due to privacy concerns and IRB restrictions but are available from the corresponding authors on reasonable request.

\section{Consent for publication}

Not applicable.

\section{Ethics approval and consent to participate}

This study was approved by the Institutional Review Board (IRB) at High Point University, IRB Protocol \#: 201501-325. Voluntary electronic consent was

obtained from all participants in accordance to the approved IRB protocol.

\section{Funding}

This work was funded by the Department of Biology at High Point University.

\section{Publisher's Note}

Springer Nature remains neutral with regard to jurisdictional claims in published maps and institutional affiliations.

Received: 13 January 2018 Accepted: 27 June 2018

Published online: 03 July 2018

\section{References}

1. AAAS. Vision and change: a call to action. AAAS, Washington DC. 2009. http://visionandchange.org/files/2013/11/aaas-VISchange-web1113.pdf. Accessed 17 Nov 2017.

2. AAAS. Vision and change in undergraduate biology education: chronicling change, inspiring the future. AAAS, Washington DC. 2015. http://visionandchange.org/files/2015/07/NISchange2015_webFin.pdf. Accessed 17 Nov 2017

3. Woodin T, Carter VC, Fletcher L. Vision and change in biology undergraduate education, a call for action -initial responses. CBE Life Sci Educ. 2010;9:71-3.

4. Gormally C, Brickman P, Lutz M. Developing a test of scientific literacy skills (TOSLS): measuring undergraduates' evaluation of scientific information and arguments. CBE Life Sci Educ. 2012;11:364-77.

5. Abdelfattah F. The relationship between motivation and achievement in low-stakes examinations. Soc Behav Pers Int J. 2010;38:159-67.

6. Silm G, Must O, Täht K. Test-taking effort as a predictor of performance in low-stakes tests. TRAMES. 2013;17:433-48.

7. Wise SL, DeMars CE. Low examinee effort in low-stakes assessment: problems and potential solutions. Educ Assess. 2005;10:1-17.

8. Wise SL. An investigation of the differential effort received by items on a low-stakes computer-based test. Appl Meas Educ. 2006;19:95-114.

9. Wise SL. Strategies for managing the problem of unmotivated examinees in low-stakes testing programs. J Gen Educ. 2009;58:152-66.

10. Barry CL, Horst SJ, Finney SJ, Brown AR, Kopp JP. Do examinees have similar test-taking effort? A high-stakes question for low-stakes testing. Int J Test. 2010;10:342-63.

11. Wise SL, Kong X. Response time effort: a new measure of examinee motivation in computer-based tests. Appl Meas Educ. 2005:18:163-83.

12. Chapell MS, Blanding ZB, Silverstein ME, Takahashi M, Newman B, Gubi A, McCann N. Test anxiety and academic performance in undergraduate and graduate students. J Educ Psychol. 2005;97:268-74.

Ready to submit your research? Choose BMC and benefit from:

- fast, convenient online submission

- thorough peer review by experienced researchers in your field

- rapid publication on acceptance

- support for research data, including large and complex data types

- gold Open Access which fosters wider collaboration and increased citations

- maximum visibility for your research: over 100M website views per year

At BMC, research is always in progress.

Learn more biomedcentral.com/submissions 